\title{
Early outcome of facial reconstructive surgery abroad: a comparative study
}

\author{
Roos Marck • Marijn Huijing • Deborah Vest • \\ Mekonen Eshete $\cdot$ Klaas Marck • Mark McGurk
}

Received: 5 October 2009 / Accepted: 8 February 2010 /Published online: 5 March 2010

(C) The Author(s) 2010. This article is published with open access at Springerlink.com

\begin{abstract}
Every year, many medical missions are undertaken in the developing world but there is almost a universal lack of outcome data on the quality of these missions. The present study compares early clinical outcome and complication rate in two consecutive missions (facial reconstruction) undertaken to Ethiopia in 2007 and 2008. The object was to establish if measures adopted following feedback from the first mission led to improvement of the results. A significant improvement was observed in early clinical outcome and there were less
\end{abstract}

R. Marck

Department of Surgery, St. Lucas Andreas Hospital,

Jan Tooropstraat 164 ,

1061 AE Amsterdam, The Netherlands

\section{Huijing}

Department of Plastic Surgery,

University Medical Centre Groningen,

Hanzeplein 9713GZ,

Groningen, The Netherlands

D. Vest

SHO Surgery Guy's and St Thomas' Hospital,

London, England

M. Eshete

Yekatit 12 Hospital, Medical Faculty,

Addis Ababa, Ethiopia

K. Marck $(\triangle)$

De Pôlle 24,

9084BT Goutum, The Netherlands

e-mail: k.marck@chello.nl

\section{McGurk}

Department of Oral and Maxillofacial Surgery,

Dental Institute at Guy's, King's College \& St Thomas' Hospitals,

London, England severe complications in the 2008 compared to the 2007 mission. On both occasions, significantly more complications were experienced after complex compared to simple procedures. Despite improved outcome in $2008,50 \%$ of the complex cases had an unfavourable clinical result. The data suggest that early outcome studies are a useful method of critically evaluating the quality of surgical mission. The unsatisfactory outcome of complex procedures underlines the need for feedback on the quality of these missions.

Keywords Facial reconstructive surgery · Noma .

Clinical outcome $\cdot$ Complications $\cdot$ Medical mission

\section{Introduction}

Each year, thousands of short-term (2-3 week) medical missions are undertaken with the intention of bringing humanitarian health care and medical education to the developing world [1]. Many of these are involved in facial reconstruction including cleft lip and palate, noma and postburn surgery.

The literature detailing these activities is scarce and, when present, is dominated by descriptions of techniques to overcome particular surgical challenges rather than record the quality of results obtained. Consequently, concern has started to be expressed about the objectives and results of overseas surgical missions [2] for even the most experienced teams encounter problems which, in extreme instances, can result in operative deaths [3, 4]. Huijing et al. [5] were one of the first to report on the results of the treatment of patients with gross facial deformity. The outcomes were not always as favourable as initially supposed. In western medicine, quality evaluations are now becoming integral to treatment provision [6] but for obvious reasons this 
standard of care is difficult to apply to short charitable missions. Maki et al. [1] recommended a critical analysis of mission- specific outcomes to promote a discussion on how to optimise quality.

The aim of the present study is to compare outcomes of two surgical missions undertaken in Addis Ababa in 2007 and 2008. Analysis of outcomes of the first mission in 2007 [5] demonstrated the importance of the multifactorial aspects of management such as nutritional status, personal hygiene and postoperative care on the quality of results rather than surgical planning and expertise alone. Consequently, changes were introduced in the second mission to improve these aspects of care. The object of this study was to establish whether the changes had a positive impact on outcome.

\section{Patients and methods}

The two surgical missions were funded and organised by the charity Facing Africa at Yekatit 12 Hospital in Addis Ababa in October 2007 and 2008. The composition of the 2008 team was essentially the same as the 2007 mission, with three maxillofacial surgeons, two plastic surgeons, two anaesthetists, two nurses (theatre and ward duties), two junior doctors, a dentist, a medical student and two nonmedical managers from the organising charity.

The case mix consisted half of noma cases and was comparable in content and severity to cases treated in the 2007 mission (Table 1). Forty-two patients were treated in 2008 compared to 35 in 2007 , and 48 operations were performed, including 12 submental flaps, nine nasolabial flaps and a radial free flap. In the 2008 mission, 26 treatments were classified as simple procedures and 16 as complex, compared to 17 and 18, respectively, in 2007.

Data was collected prospectively and included patient history, age, sex, operative details and complications. The

Table 1 Patient characteristics and pathology mix of both missions

\begin{tabular}{lrrr}
\hline Patient characteristics & Mission 2007 & Mission 2008 & Total \\
\hline Number of patients & 35 & 42 & 77 \\
Mean age in years (range) & $25(9-60)$ & $23(7-40)$ & \\
Female & 20 & 19 & 39 \\
Male & 15 & 23 & 38 \\
Simple treatment & 17 & 26 & 43 \\
Complex treatment & 18 & 16 & 34 \\
Pathology mix & & & \\
Noma & 17 & 20 & 37 \\
Trauma & 7 & 6 & 13 \\
Tumours & 3 & 3 & 6 \\
Various & 8 & 12 & 20 \\
\hline
\end{tabular}

noma patients were classified by the NOITULP-classification [7]. Daily clinical and photographic records were kept over the treatment and convalescent period (up to 5 weeks post surgery). The data was compiled and adjudicated by a senior plastic surgeon experienced in noma surgery (KM), who was not part of the visiting surgical team.

The surgical procedures were classified as simple or complex. Simple procedures consisted of local excisions, extirpations and reconstructive procedures such as a skin graft or a local transposition flap. Treatments that involved significant tissue transfer (pedicled flaps and free flaps) or several stages in execution (delayed or prefabricated flaps) were considered complex. In concordance with the 2007 study, complications were classified by severity: major (life-threatening), intermediate (stay longer than anticipated) and minor (discharged at expected time) or no complications.

Patient outcome was determined in an aesthetic and, where possible (mouth opening, presence of dribbling), functional perspective, and graded into one of five outcome categories based on intended versus actual outcome: $1=$ very poor (worse than before; 2 = poor (no improvement obtained); 3 = mediocre (moderate improvement); $4=$ satisfactory (acceptable but not as good as anticipated); and $5=$ excellent (as anticipated) and these were grouped into two categories for analysis: unsuccessful outcome (categories 1,2 and 3) and successful outcome (categories 4 and 5). The outcome parameters were identical to those used in 2007 [5].

In view of experiences and results of the 2007 missions, the following changes were made to the organisation and planning of the 2008 mission. The patients were admitted 2 weeks prior to arrival of the team in order to prepare them for surgery. This included dental care, hyperalimentation, multivitamin and antihelminthic treatment and measures of general hygiene. In 2007, due to pressure of time, only a brief meeting was held to plan cases prior to surgery whereas in 2008, more detailed patient information was collected prior to the surgical team's arrival. This facilitated an informed in-depth discussion on management of each case. Surgical procedures remained essentially the same. In noma patients, scar tissue was excised, ankylosed jaws were released and for inner lining, the (prefabricated) temporoparietal fascia flap (TPF) was used. One change was that the pedicled deltopectoral flap used for external cheek cover in 2007 was abandoned in 2008 for the locally based submental flap. Nasolabial and forehead flaps were used for reconstruction of nasal deformities and in 2008, (one) microvascular free flap transfer was undertaken.

Important changes were introduced to postoperative care for in 2008, one nurse was allocated specific responsibility for ward-based wound care, and both antibiotics and nasal gastric tubes were used routinely. 
Treatment outcome for each year was analysed by complexity of surgery and then collectively $(2007+2008)$ by comparing the occurrence of complications and outcome scores using the Pearson Chi-square test (SPSS-16.0), with significance set at $P<0.05$.

\section{Results}

Most complications in both 2007 and 2008 related to wound-healing problems (necrosis, dehiscence and infection, often in combination). There was a trend in the 2008 data for complications to be both less frequent and less severe but the differences are not significant (Table 2).

Table 3 shows, for both missions, the distribution of the early clinical outcome over the five outcome categories. Figure 1 shows a patient with an unsuccessful outcome and Fig. 2 a patient with a successful outcome. Comparison of clinical outcome (Fig. 3) between 2007 and 2008 (success = $4 / 5$ : unsuccessful $=1 / 2 / 3$ ) demonstrated a significant improvement in 2008 results (Chi-square test; $P=0.04$ ).

In 2008, a successful outcome was obtained in $92 \%$ (24/ $26)$ of the simple cases as compared to $82 \%(14 / 17)$ in 2007. Of the complex cases in 2008, 50\% (8/16) had a successful outcome, as compared with 28\% (5/18) in 2007.

The 2007 and 2008 data sets were combined and analysed by complexity of operation. The results show that $49 \%(21 / 43)$ of the simple and 100\% (34/34) of complex procedures were accompanied by at least one complication. The difference is highly significant $(P<0.0001)$. In sympathy with the above data, $88 \%(38 / 43)$ of patients with simple procedures obtained the intended surgical result but only 38\% (13/34) following complex surgery $(P<0.0001)$.

\section{Discussion}

The aim of this study was to compare the results of two consecutive surgical missions in order to find out if a number of measures introduced to improve preoperative assessment, surgical planning and postoperative care had been successful. These changes to patient care were

Table 2 Number and percentage of complications of both missions

\begin{tabular}{lcc}
\hline Complications & Mission 2007 & Mission 2008 \\
\hline None & $9(26 \%)$ & $14(33 \%)$ \\
Minor & $5(14 \%)$ & $12(29 \%)$ \\
Intermediate & $19(54 \%)$ & $16(38 \%)$ \\
Major & $2(6 \%)$ & $0(0 \%)$ \\
\hline
\end{tabular}

${ }^{\text {a }}$ Difference in severity of complications between the two missions n.s.
Table 3 Number and percentage of early clinical outcome scores of both missions

\begin{tabular}{lcc}
\hline Outcome & Mission 2007 & Mission 2008 \\
\hline Worse than before & $4(11 \%)$ & $3(5 \%)$ \\
Same as before & $5(14 \%)$ & $1(2 \%)$ \\
Mediocre & $7(20 \%)$ & $7(17 \%)$ \\
Acceptable & $9(26 \%)$ & $18(43 \%)$ \\
Good & $10(29 \%)$ & $14(33 \%)$
\end{tabular}

${ }^{\mathrm{a}}$ Difference in severity of outcome in five classes between the two missions n.s.

instituted as a result of unfavourable results obtained in the initial surgical mission of 2007 where $74 \%$ of the patients encountered a complication and only $82 \%$ of simple and $28 \%$ of complex surgery achieved a satisfactory clinical outcome [5].

The results of the present study show that the changes introduced resulted in a significant improvement of the early clinical outcome. It is not possible to place the
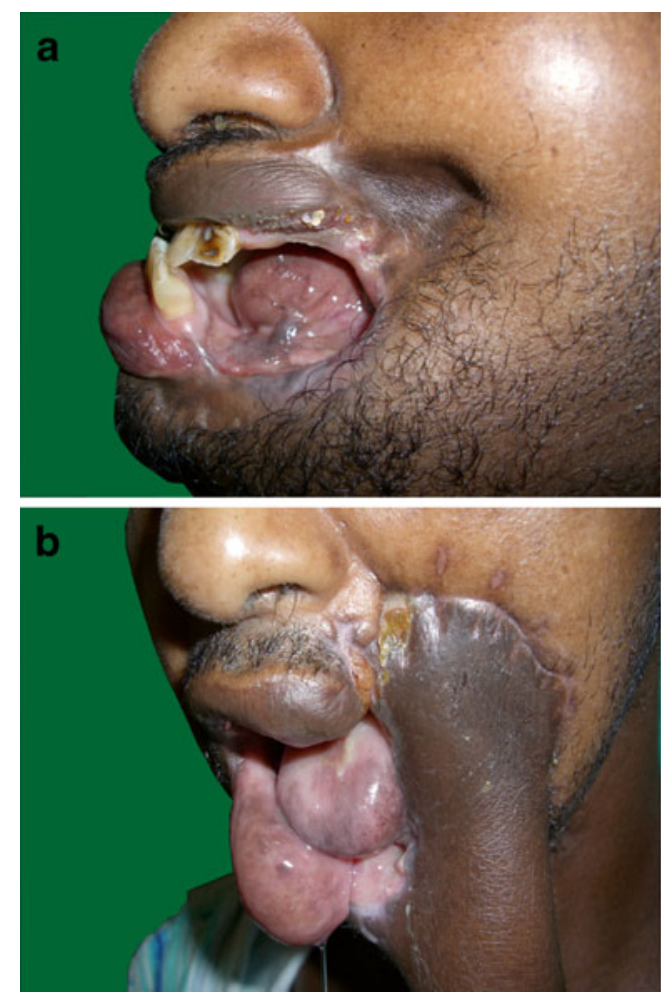

Fig. 1 a Patient with a noma defect of the upper and lower lip and of the cheek and ankylosis of the temporomandibular joint, classified as N-0, O-3, I-4, T-3, U-1, L-2, P-0. b After prefabrication of a temporal fascia flap and delay of a deltopectoral flap one week earlier, scar excision was done and bilateral trismus release with a gap osteotomy on the left side, followed by reconstruction with the prefabricated temporal fascia flap and the delayed deltopectoral flap. Postoperatively, necrosis of the fascia flap was noted, as well as wound dehiscences and infection. Early clinical outcome classified as 4 (poor) 

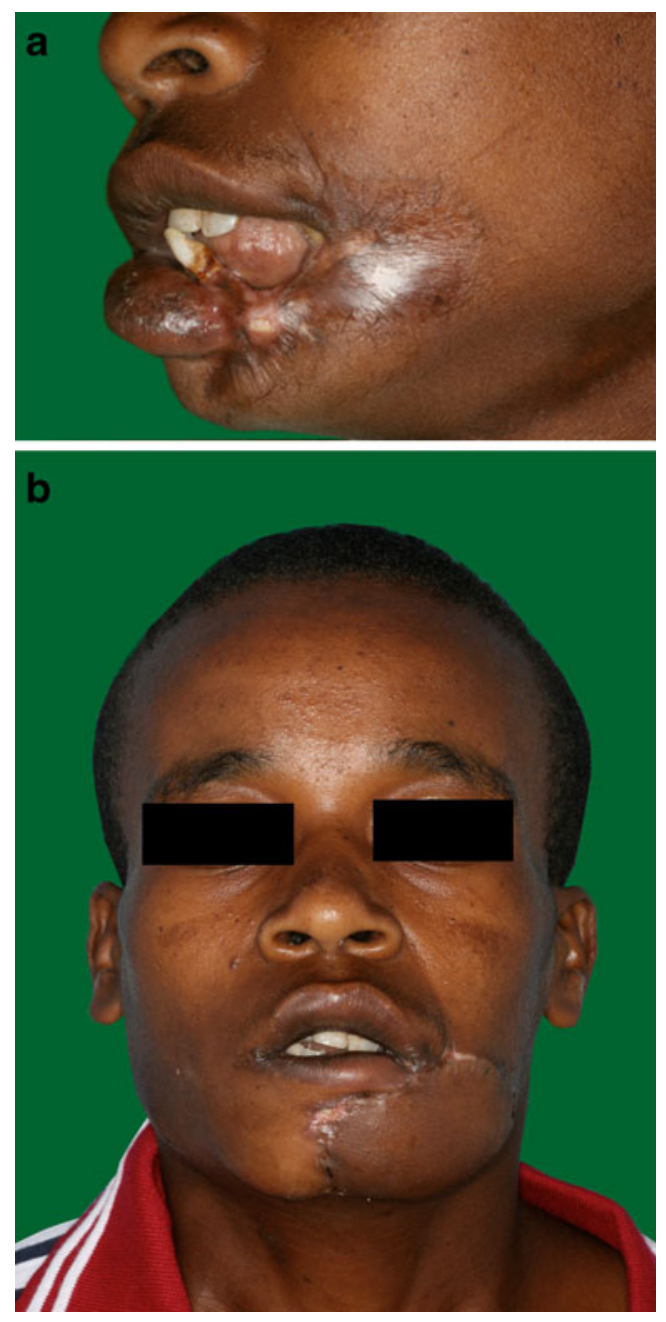

Fig. 2 a Patient with a noma defect of the upper and lower lip and of the cheek, classified as N-0, O-1, I-0, T-0, U-2, L-2, P-0. b Ten days after treatment that consisted of scar excision and reconstruction with a submental flap. Early clinical outcome classified as 1 (excellent)

changes within a range of effectiveness. Measures such as early admission, improved nutrition, dental/general hygiene treatment of concomitant infections and better surgical planning are all likely to have helped improve outcome. The old adage of the pioneer of noma surgery, Michael Tempest, to keep this surgery simple, sound and satisfactory [8] is borne out by the good outcome following simple procedures.

A major change in 2008 was the introduction of the submental flap (Fig. 2). This avoided the use of the deltopectoral flap, which carries a high morbidity especially in children. The submental flap has two advantages, it carries hardly any donor site morbidity and the graft colour is an excellent match for facial skin $[9,10]$. However, the blood supply to the tip of the flap is a little precarious. Free flap surgery (a radial forearm flap in a healthy adult noma patient) contributed to the good results and demonstrated that microvascular reconstructions are feasible in these settings [11] but have limitations [12].

A third and important development was the attention paid to postoperative wound care.

Nasal gastric tube feeding was introduced to avoid soiling of the oral cavity and the incision lines and wounds were dressed at least twice a day (antiseptic ointment). A low threshold was adopted for debridement of infected wounds and each patient was given a week of prophylactic antibiotics.

Despite this careful planning and preparation, the results achieved in the complex cases were still unsatisfactory in $50 \%$ of the cases treated. Without the use of outcome studies, this imbalance between what was planned and what was actually achieved would not have been appreciated.

There are limitations to the present study. Firstly, the sample group was too small to compare results in the five categories of clinical outcome. Furthermore, there is a potential source of bias in the retrospective nature of assessment. Even though the adjudicating surgeon was independent of the surgical teams, the assessment of results is still made from a personal perspective. Despite these limitations, an early outcome study as described, seems to be a good quality indicator for a surgical mission. An analysis of late results is the ultimate test of quality but this is hard to achieve in an African setting. The patients were recruited from long distances and had no resources with which to make a return journey for purposes of follow up. Thus, early outcome evaluation is likely to be the only quality measure that is practical.

Our first early outcome study [5] made it possible to give feed back to the surgical team in order to consider



Fig. 3 The number of patients of both missions with successful and unsuccessful results. In 2008 , significantly $(P<0.05)$ more good results have been obtained 
measures of improvement. This (second) early outcome study has been used to find out if a bundle of measures to improve the clinical results has been effective, which appears to be the case.

Fundamental questions still remain to be resolved. Similar high rates of complications and unfavourable (early) outcomes have also been observed after two missions in the Noma Children Hospital in Sokoto, Nigeria, both manned with (also noma) highly experienced plastic surgeons [13]. This indicates that technically demanding and lengthy reconstructive procedures under less privileged circumstances (technical infrastructure, theatre, lack of reliable laboratory and intensive care facility, unknown concomitant patient diseases, unknown microbiological hazards as sterilisation procedures, lack of hygiene in the theatre and on the ward) go hand in hand apparently with a complication rate and early outcomes that are far below Western standards.

These inconvenient findings are in contrast with the results of cleft lip surgery during a short mission as reported by McQueen et al. [14] and experienced by ourselves.

In view of the tendency with short surgical visits to see mainly the positive aspects of treatment, a quality indicator like this early outcome study seems to be an invaluable tool for facial reconstructive surgery missions other than cleft surgery. They may be useful to judge the standard of care, to identify risk profiles in patients and infrastructure, to develop a performance indicator and standards and allow measures to be introduced to improve future results.

Acknowledgements This study was made possible by support from Facing Africa and the Dutch Noma Foundation.

Open Access This article is distributed under the terms of the Creative Commons Attribution Noncommercial License which per- mits any noncommercial use, distribution, and reproduction in any medium, provided the original author(s) and source are credited.

\section{References}

1. Maki J, Qualls M, White B, Kleefield S, Crone R (2008) Health impact assessment and short-term medical missions. A methods study to evaluate quality of care. BMC Health Serv Res 8:121-128

2. Dupuis CC (2004) Humanitarian missions in the Third World: a polite dissent. Plast Reconstr Surg 113:433-435

3. Smoot EC, Johnson M, Graham DR, Draper GA (1992) Operating safely in an underdeveloped country. Cleft Palate Craniofac J 29:444-450

4. Eberlin KR, Zaleski KL, Snyder HD, Hamdan US (2008) Quality assurance guidelines for surgical outreach programs: a 20-year experience. Cleft Palate Craniofac J 45:246-255

5. Huijing M, LeRoux F, Mizen K, Combes J, Befikadu S, Demisse J, Marck K, McGurk M (2010) Facial reconstruction in the developing world: a complicated matter. Br J Oral Maxillofac Surg in press

6. Grol R (2001) Improving the quality of medical care: building bridges among professionals pride, payer profit, and patient satisfaction. JAMA 286:2578-2585

7. Bos K, Marck K (2006) The surgical treatment of noma. Belvédère/Medidact Alphen a/d Rijn, The Netherlands

8. Tempest M (1966) Cancrum oris. Br J Surg 53:949-969

9. Martin D, Pascal JF, Baudet J et al (1993) The submental island flap: a new donor site. Anatomy and clinical applications as a free or pedicled flap. Plast Reconstr Surg 92:867-873

10. Barthlémy I, Martin D, Sannajust JP, Marck K, Pistre V, Mondié JM (2002) Prefabricated superficial temporal fascia flap combined with a submental flap in noma surgery. Plast Reconstr Surg 109:936-940

11. Giessler GA, Schmidt A (2003) Noma: experiences with a microvascular approach under West African conditions. Plast Reconstr Surg 112:947-956

12. Marck KW (2003) Discussion. Noma: experiences with a microvascular approach under West African conditions. Plast Reconstr Surg 112:955-956

13. Bouman MA, Marck KW, Griep JEM et al. (2010) Early outcome of noma surgery. J Plast Reconstr Aesthet Surg in press

14. McQueen KA, Magee W, Crabtree T, Romano C, Burkle FM Jr (2009) Application of outcome measures in international humanitarian aid: comparing indices through retrospective analysis of corrective surgical care cases. Prehosp Disaster Med 24:39-46 